\title{
As três dimensões da guerra comercial entre China e EUA
}

\author{
The three dimensions of the trade \\ war between China and the USA
}

\section{Las tres dimensiones de la guerra comercial entre China y EEUU}

DOI: 10.21530/ci.v16n2.2021.1122

Diego Pautasso ${ }^{1}$

Tiago Soares Nogara ${ }^{2}$

Carlos Renato Ungaretti ${ }^{3}$

Ana Maria Prestes Rabelo 4

\section{Resumo}

Copyright:

- This is an open-access article distributed under the terms of a Creative Commons Attribution License, which permits unrestricted use,

distribution, and reproduction in any medium, provided that the original author and source are credited.

- Este é um artigo publicado em acesso aberto e distribuído sob os termos da Licença de Atribuição Creative Commons, que permite uso irrestrito, distribuição e reprodução em qualquer meio, desde que $o$ autor $\mathrm{e}$ a fonte originais sejam creditados.
$\mathrm{O}$ artigo argumenta que a Guerra Comercial entre EUA e China engloba três dimensões: num nível mais superficial, representa o recrudescimento do protecionismo estadunidense voltado à base eleitoral de Trump e à consequente barganha em relação à China para diminuir os déficits comerciais; no nível intermediário, a disputa pela liderança de importantes segmentos tecnológicosprodutivos; e no nível mais profundo, a própria contenda pela liderança do sistema internacional. Consequentemente,

1 Doutor em Ciência Política pela Universidade Federal do Rio Grande do Sul (UFRGS). Professor do Colégio Militar de Porto Alegre. Rio Grande do Sul, Brasil. (dgpautasso@gmail.com). ORCID: https://orcid.org/0000-0002-2393-1903.

2 Doutorando em Ciência Política na Universidade de São Paulo (USP). Mestre em Relações Internacionas pela Universidade de Brasília (UnB). (tiagosnogara@gmail.com). ORCID: https://orcid.org/0000-0003-1560-8150.

3 Mestrando no Programa de Pós-Graduação em Estudos Estratégicos Internacionais (PPGEEI), da Universidade Federal do Rio Grande do Sul (UFRGS). (renato.ungaretti94@gmail.com). ORCID: https://orcid.org/0000-0002-1599-2941.

4 Doutora em Ciência Política pela Universidade Federal de Minas Gerais (UFMG). Assessora Técnica na Câmara dos Deputados. Brasília, Distrito Federal, Brasil. (anamprestes@gmail.com). ORCID: https://orcid.org/0000-0003-0521-035X.

Artigo submetido em 21/09/2020 e aprovado em 25/04/2021. 
demonstramos que a disputa tecnológica sino-estadunidense no setor da infraestrutura 5G da empresa chinesa Huawei reflete uma competição mais abrangente pela própria liderança do sistema internacional.

Palavras-chave: Guerra Comercial; Estados Unidos; China; Hegemonia; 5G.

\begin{abstract}
The article argues that the US-China Trade War encompasses three dimensions: on a superficial level, it represents the resurgence of US protectionism aimed at Trump's electoral base and the consequent bargain in relation to China to reduce trade deficits; at the intermediate level, the dispute for the leadership of important technological-productive segments; and at the deepest level, the contention for the leadership of the international system. Consequently, we demonstrate that the dispute in the 5G infrastructure sector of the Chinese company Huawei reflects a deepest competition for the leadership of the international system.
\end{abstract}

Keywords: Trade War; United States of America; China; Hegemony; 5G.

\title{
Resumen
}

El artículo sostiene que la Guerra Comercial entre Estados Unidos y China abarca tres dimensiones: en un nivel más superficial, representa el resurgimiento del proteccionismo estadounidense dirigido a la base electoral de Trump y el consecuente pacto en relación con China para reducir los déficits comerciales; en el nivel intermedio, la disputa por el liderazgo de importantes segmentos tecnológico-productivos; y en el nivel más profundo, la misma contienda por el liderazgo del sistema internacional. En consecuencia, demostramos que la disputa tecnológica chino-estadounidense en el sector de infraestructura 5G de la empresa china Huawei refleja una competencia por el liderazgo del sistema internacional.

Palabras clave: Guerra comercial; Estados Unidos; China; Hegemonía; 5G.

\section{Introdução}

A Guerra Comercial entre EUA e China engloba três dimensões. Num nível mais superficial, representa o recrudescimento do protecionismo estadunidense voltado à base eleitoral de Trump e à consequente barganha em relação à China para diminuir os déficits comerciais. Contudo, pretendemos argumentar, 
neste artigo, que esse tensionamento bilateral encerra disputas mais profundas: no nível intermediário, pela liderança de importantes segmentos tecnológicosprodutivos e, no nível mais profundo, pela liderança do sistema internacional. O problema de pesquisa em questão é, pois, compreender como as disputas tarifárias obscurecem a rivalidade sino-americana e, com efeito, a liderança técnico-produtiva e sistêmica em jogo. Para lançar luz sobre essa problemática, buscamos enfatizar a questão do padrão tecnológico 5G e da empresa chinesa líder no setor, a Huawei, como referente empírico.

Nesse sentido, situamos as contradições no seio das relações sinoestadunidenses como parte de uma complexa transição sistêmica. Trata-se de uma premissa teórica ancorada na obra de Arrighi e Silver (2001), que indica o acirramento das competições interestatais e interempresariais nas conjunturas de reorganização das bases técnico-produtivas globais. Desde a década de 1970, as reorganizações geoeconômica e geopolítica têm envolvido processos complexos e entrelaçados, tais como a reação neoconservadora e neoliberal, a emergência de novos paradigmas produtivos, o final da Guerra Fria, a projeção de poder dos EUA e, com a virada para o século XXI, a crescente multipolarização. Está cada vez mais perceptível a intensificação da competição político-econômica entre os países mais poderosos, com a redução da capacidade arbitral (unilateral) dos EUA, a rápida fragmentação do sistema mundial, falência e esvaziamento de organismos multilaterais, a volta da luta pelas supremacias regionais e, como efeito, o aumento do grau de incerteza no mundo (Fiori 2007). Nesse sentido, a pandemia parece ter precipitado tanto inovações quanto tendências disruptivas, acelerando dinâmicas sistêmicas e recrudescendo as contradições entre EUA e China.

Para dar conta desse tema, o artigo está organizado da seguinte forma. A primeira parte aborda a ascensão chinesa após a política de Reforma e Abertura, num quadro de reorganização sistêmica. A segunda, trata da Guerra Comercial, relatando sua cronologia, bem como suas três dimensões entrelaçadas. Por fim, a última seção discute como a disputa tecnológica sino-estadunidense no setor da infraestrutura 5G da empresa chinesa Huawei reflete uma competição mais abrangente. 


\section{A ascensão chinesa num quadro de transição sistêmica e a reação estadunidense}

A ascensão da China tem coincidido com o processo de reorganização do sistema internacional. A política de Reforma e Abertura, de Deng Xiaoping, foi desencadeada, na década de 1970, de modo a inaugurar um novo ciclo de desenvolvimento e inserção global para o país asiático. Como destaca Pinto (2011), a construção do eixo sino-americano articulou a globalização financeira estadunidense ao embrionário milagre econômico chinês, impulsionando mudanças significativas na divisão internacional do trabalho e, consequentemente, nas configurações de poder no mundo. O irrefreável desenvolvimento da China, a partir do século XXI, passou a tensionar as estruturas hegemônicas de poder centradas nos EUA e nos seus aliados.

O desenvolvimento chinês se desdobrou em três processos fundamentais, no âmbito do seu comércio exterior, nas últimas décadas do século XX: 1) expansão dos fluxos de comércio e participação chinesa no comércio global; 2) sofisticação da pauta do comércio externo do país, que resultou na consolidação de um setor exportador dinâmico e com crescente intensidade tecnológica; 3) e redirecionamento dos fluxos de comércio, em especial das exportações, no qual os EUA se constituíram no principal mercado consumidor e as nações asiáticas se tornaram as principais fornecedoras para a produção desses bens exportados (Chernavsky e Leão 2011).

Vamos aos dados. Segundo o Atlas da Complexidade Econômica, a China possuía índice de complexidade econômica de 0,143 em 1995 e 1,16 em 2016, passando de $50^{\circ}$ para $18^{\circ}$ no ranking mundial - no mesmo período, os Estados Unidos passaram de 1,86 para 1,55 , ou da $7^{\text {a }}$ para a $10^{a}$ posição. Em 1992, pouco mais de $6 \%$ das exportações chinesas eram formados por bens de alto valor agregado (high-technology), chegando a mais de $25 \%$ em 2016 - enquanto os EUA, no mesmo período, viram despencar de $32,5 \%$ para $19,9 \%$ a participação dos bens com alto valor agregado na sua pauta de exportações. Em 2017, as exportações chinesas totalizaram US $\$ 1,95$ trilhões e os principais destinos dessas exportações foram: EUA (US \$ 425 bilhões), Japão (US\$ 136 bilhões), Alemanha (US\$ 71 bilhões) e Coréia do Sul (US\$ 100 bilhões) (OEC, 2018). 
Em relação à composição das exportações, $49 \%$ são classificadas como máquinas 5 , ao passo que os principais produtos exportados, em 2016, foram: 1) ferramentas de transmissão de radiotelefonia; 2) circuitos integrados eletrônicos; 3) máquinas automáticas de processamento de dados; 4) aparelhos elétricos de telefonia (OMC, 2020). Depreende-se, nesse sentido, que a evolução das exportações chinesas transitaram de um padrão exportador de commodities e de produtos de baixo valor agregado (Chernavsky e Leão 2011) para um padrão exportador esmagadoramente composto por produtos manufaturados ${ }^{6}$, sendo mais de $90 \%$ de suas exportações em produtos manufaturados.

Não obstante, as dificuldades de mensuração de dados variáveis, como controle acionário e perfil das empresas, trata-se de uma ascensão significativa de 18 empresas chinesas, em 2005, para 124 listadas (133 se contar Taiwan) entre as 500 maiores do mundo, em 2020, segundo a Fortune - enquanto, nesse mesmo período, os EUA passaram de 176 para 121 no primeiro ano em que foram superados pelo país asiático (Murray e Meyer, 2020). É evidente que as estratégias Going Global e Made in China 2025 são a expressão dessa nova etapa qualitativa do desenvolvimento chinês e aprofundam a concorrência interempresarial da qual falava Arrighi (1996). E com a crise de 2008 e a liderança de Xi Jinping (2012), nota-se um aprofundamento dessa postura mais assertiva da China, especialmente no campo da diplomacia econômica (Daojiong 2015). Os textos oficiais de Xi Jinping tratam da Diplomacia de Grande País em consonância com a grande revitalização nacional, enquanto ensejam a retórica do benefício mútuo, da cooperação ganha-ganha e do desenvolvimento compartilhado, mas sem deixar de lado o crescente protagonismo na governança global através do multilateralismo, visando a reforma do sistema internacional (Jinping, 2018).

A China atua de maneira cada vez mais assertiva no atual sistema de governança, como no G20 (comercial e financeiro), ou mesmo fazendo gestões para reformá-lo, como no Fundo Monetário Internacional (FMI). Ao mesmo tempo, a China lidera diversas iniciativas para criar estruturas de governança paralelas: no âmbito financeiro, Banco Asiático de Investimentos em Infraestrutura

5 De acordo com o OEC (2018), os principais produtos computados dentro dessa categoria foram: equipamento de transmissão (US\$ 231 bilhões), computadores (US\$ 146 bilhões), peças de máquinas de escritório (US\$ 90,8 bilhões), circuitos integrados (US\$ 80,1 bilhões) e telefones (US\$ 62 bilhões).

6 Segundo a OMC (2020), em 2018, cerca de $93 \%$ das exportações chinesas foram de produtos manufaturados, ao passo que os outros $7 \%$ restantes se dividem em produtos agrícolas e combustíveis e produtos minerais, sobretudo. 
(AIIB), Novo Banco de Desenvolvimento dos BRICS (NDB/BRICS), Sistema de Pagamento Internacional da China, China UnionPay, Grupo de Avaliação de Crédito Universal; no âmbito integrativo (comercial e securitário), Parceria Econômica Regional Abrangente, Organização para Cooperação de Xangai, BRICS, Fórum Boao para a Ásia; no âmbito infraestrutural, a Nova Rota da Seda ou Iniciativa Cinturão e Rota (Stuenkel 2018).

Mas sem dúvida, a mais audaciosa ação diplomática da China tem sido a Nova Rota da Seda (Belt and Road Initiative-BRI). A iniciativa de Beijing representa a etapa regional do projeto chinês de globalização e, com efeito, tensiona com a primazia global estadunidense. A BRI é um evidente transbordamento do desenvolvimento da China e cumpre diversos objetivos articulados: 1) cria demanda para a supercapacidade ociosa da indústria nacional; 2) amplia a segurança em recursos naturais, energéticos e alimentares; 3 ) impulsiona a internacionalização das empresas chinesas e a exportação de serviços (de engenharia, especialmente); 4) fortalece o comércio regional e o papel gravitacional da China na recriação do sistema sinocêntrico; 5) contribui para securitizar a partir do desenvolvimento e da integração regionais; 6) e fomenta a conversibilidade do renmimbi (RMB), tornando a moeda chinesa reserva de valor e meio de comércio corrente ${ }^{7}$. A simbiose entre seu desenvolvimento e seu poder global ${ }^{8}$ demonstra o entrelaçamento entre a BRI e o Made in China 2025 - e deixa claro o papel do país de agente ativo na reconfiguração do sistema internacional (Yiwei 2016). Está posto, pois, que a crescente vantagem chinesa na competição interempresarial, e o enlace de suas corporações com o Estado chinês, tem influenciado o deslocamento de processos decisórios e produtivos e a emergência de novas configurações de poder no mundo, quiçá, sinocentradas como colocava Arrighi (1996; 2008).

Nesse sentido, alguns dados podem ajudar a iluminar as novas capacidades do país asiático, bem como as contradições que encerram com as potências consolidadas (EUA, Alemanha, Japão, etc.). Em termos de riqueza absoluta, a China se tornou o maior PIB mundial em poder de paridade de compra já em 2014, enquanto em dólares, seu PIB (US\$13,5 trilhões em 2018) é equivalente ao dos próximos quatro países juntos (Japão, Alemanha, Reino Unido e França). Em termos comerciais, o país se tornou o maior exportador, em 2009, e é responsável por $40 \%$ do tráfego de contêineres, tendo 7 dos 10 maiores portos do mundo;

\footnotetext{
7 Ver Pautasso (2019a).

8 Ver Pautasso (2019b).
} 
é o principal parceiro comercial de 130 países; tem $42 \%$ do e-commerce mundial. Em termos produtivos, a produção manufatureira da China já é o dobro da dos EUA, tem contribuído com cerca de $28 \%$ do crescimento global; considerando Taiwan, é o país com mais empresas entre as 500 maiores da Global Fortune, marcas chinesas detêm $40 \%$ do mercado mundial de smartphones; em pouco mais de duas décadas, construiu mais de $30 \mathrm{mil} \mathrm{km}$ de ferrovias de alta velocidade. Para ilustrar: em três anos (2012-2015), a China usou mais cimento do que os EUA em todo o século XX. Em termos de inovação, o país oriental forma quatro vezes mais graduados em ciências, tecnologia, engenharia e matemática (STEM) do que os EUA; tem $40 \%$ das patentes nas tecnologias 5G. Em termos sociais, retirou 800 milhões de pessoas da pobreza extrema desde o início das reformas. Se, por um lado, os dados são surpreendentes, por outro, é inegável que os desafios também são proporcionais.

Ora, essa ascensão da China produz um profundo tensionamento global, na medida em que pressiona as estruturas hegemônicas de poder lideradas por Washington. Durante o governo Obama, a então secretária de Estado Hillary Clinton, escreveu, na Foreign Policy, artigo intitulado America's Pacific Century (out/2011). Nele, a Ásia Oriental passava a ser considerada uma região pivô - após o governo dos EUA ter dado mais ênfase ao Oriente Médio na primeira década do século XXI. As prioridades seriam a proliferação imprevisível e instável de armas nucleares da Coréia do Norte, as disputas territoriais no mar do Sul da China, e a ascensão do gigante asiático. Para tanto, os EUA deveriam fortalecer as relações com aliados históricos, como Japão, Coréia do Sul, Filipinas, Austrália e Tailândia; aprofundar as parcerias com Indonésia, Malásia, Cingapura, Vietnã e Índia e fortalecer o relacionamento não oficial com o povo de Taiwan. Naquele contexto, uma das estratégias para a região era aumentar o comércio e o investimento através do Acordo Parceria Transpacífica (TPP).

Desde a normalização das relações comerciais entre EUA e China, no ano 2000, sob a presidência de Bill Clinton, o que inclusive abriu as portas para a entrada da China na OMC (2001), a vitória de Trump foi a mudança que representou maiores alterações na política externa de Washington, sobretudo na sua interação com a China. A primeira evidência disso foi o fato de que, em seu terceiro dia no cargo, Trump assinou uma ordem executiva retirando os EUA do TPP. Além da retirada do acordo, houve um tensionamento nas relações com a China, que desde a campanha eleitoral já era alvo preferencial de críticas. A narrativa eleitoral de Trump enfatizou três temas envolvendo o comércio internacional: 1) 
balança comercial deficitária; 2) manipulação cambial - especialmente da China; 3) e acordos comerciais "desastrosos" para os EUA (Noland, 2018). Durante seu mandato, Trump perseguiu essa agenda com afinco: o país utilizou todos os mecanismos de defesa comercial a seu alcance - como é o caso do uso de leis antidumping e de direitos compensatórios e, inclusive, da invocação de leis internas para realização de atos unilaterais -, contribuindo tanto para a revisão de acordos bilaterais e regionais quanto para o desapreço dos procedimentos e das regras na esfera da OMC. De acordo com McBride (2018), o desinteresse em tratar as disputas comerciais no âmbito multilateral, somado às medidas unilaterais adotadas contra a China e outros países, vem suscitando dúvidas inclusive sobre o futuro da OMC.

Sob o comando de Trump, os EUA abandonariam a OMC e outros organismos multilaterais à própria sorte, enquanto intensificaram a disputa bilateral com a China e a autossuficiência na resolução de outras situações conflituosas, como com o Irã e a Coreia do Norte. Mais recentemente, com a pandemia, até a OMS sofreu as consequências dessa política liquidacionista dos mecanismos multilaterais de convivência internacional e de resolução de conflitos.

Em um documento elaborado pelo Congresso, em 2018, Morisson (2018) estabelece as principais preocupações dos EUA em relação às relações comerciais com a China. Além das críticas à manipulação cambial, o relatório observa as seguintes questões: a) infrações em relação à propriedade intelectual estadunidense (incluindo roubo cibernético de segredos industriais); b) crescente o uso de políticas industriais para promover e proteger indústrias domésticas chinesas; c) extensivas restrições ao investimento estrangeiro e ao comércio exterior; d) ausência de transparências nas regras e nos regulamentos comerciais; e) distorcivas políticas econômicas que tem levado à formação de capacidades ociosas em diversas indústrias; f) e elevado superávit comercial no comércio de bens com os Estados Unidos.

O fato é que o governo Trump, especialmente com a crise pandêmica, recrudesceu seus gestos. Em um de seus últimos pronunciamentos, na Comissão de Relações Exteriores do Senado americano, em julho de 2020, o Secretário de Estado, Mike Pompeo, disse que o Partido Comunista Chinês é "a principal ameaça dos nossos tempos" e que "a corrente está virando", pois o mundo estaria "despertando para isso" sob a liderança dos EUA. Como fator demonstrativo, ele citou o fato de vários países estarem "rejeitando" a Huawei em seus projetos de implantação da tecnologia de comunicação 5G. Ele defendeu ainda o fechamento 
do consulado chinês em Houston, no Texas, por se tratar de um "covil de espiões". O consulado foi fechado sob acusações de espionagem e roubo de propriedade intelectual. A China reagiu fechando o consulado de Chengdu, no sudeste do país. Na época, autoridades chinesas disseram que "os EUA violaram seriamente o direito internacional e os termos da Convenção Consular China-EUA".

A "crise dos consulados" faz parte da mais séria crise diplomática entre os dois países desde 1979; some-se a isso, as expulsões recíprocas de jornalistas, o envio de bombardeiros para a base naval norte-americana, no oceano Índico, no contexto da tensão sino-indiana no Himalaia, o congelamento de bens das autoridades de Hong Kong, a elevação da tensão no Mar do Sul da China, a perseguição ao aplicativo TikTok, que possui uma milionária rede de usuários nos EUA, a promoção do encontro diplomático de mais alto nível com as autoridades de Taiwan em 40 anos, os ataques ao novo Centro de Controle de Doenças da União Africana, em Adis Abeba, construído pelos chineses, a retórica do "vírus chinês" ao longo da pandemia e, por fim, o abandono do posto de Embaixador dos EUA na China, por Terry Branstad, velho conhecido de Xi Jinping desde os anos 80 .

Assim como a disputa tarifária, rusgas diplomáticas e confrontos acerca da governança global (em organismos internacionais) refletem a ofensiva de Washington em face da emergência da China. Isso, por sua vez, é típico da mudança de centros produtivos e decisórios a partir de novas dinâmicas entrelaçadas entre territorialidade estatal e processos globais de acumulação. Como destacou Arrighi (1996), tais dinâmicas estão no cerne das mudanças sistêmicas e das novas configurações (hierárquicas) de poder no mundo.

\section{As três dimensões da Guerra Comercial}

Como sugerimos, a Guerra Comercial tem três dimensões. Para além da tarifária, a questão tecnológica parece ser a mais sensível, pois trata-se da liderança sobre os novos paradigmas produtivos, com impactos no longo prazo para a própria transição sistêmica. O caso da infraestrutura de comunicação 5G, tendo como epicentro a empresa chinesa Huawei, talvez seja ilustrativo das disputas em questão e de seus efeitos sobre a ordem mundial em conformação.

Para compreender essas disputas tecnológicas, cabe recapitular o quadro geral da Guerra Comercial. Antes de qualquer coisa, o crescente déficit comercial dos 
EUA com a China foi se tornando complicado. Dessa forma, a eleição de Trump, em 2016, se nutriu justamente da retórica antichinesa, pois convergia tanto com sua base eleitoral mais conservadora quanto com setores produtivos nacionais, ambos interessados no protecionismo e nos empregos. Assim, sob a bandeira do America First, as ações do governo estadunidense foram desencadeadas a partir de 6 de julho de 2018, quando entrou em vigor tarifas sobre 818 produtos exportados pela China, contabilizando um valor de US\$ 34 bilhões (Quadro 1). $O$ resultado foi que o déficit comercial bilateral anual caiu pela primeira vez em tempos recentes, no ano de 2019, chegando a US\$345,6 bilhões, ante os US \$ 418,9 bilhões de 2018. O ano de 2020 corrobora a tendência, apontando perspectivas para nova redução: entre janeiro e maio, o déficit com a China ficou em US\$ 103,3 bilhões, bem abaixo dos US\$ 136,4 bilhões do mesmo período do ano passado.

Quadro 1 - Cronologia da guerra comercial

\begin{tabular}{|c|c|}
\hline Data & Acontecimento \\
\hline 06/07/2018 & EUA impõem tarifas sobre importações chinesas no valor de US\$ 34 bilhões. \\
\hline $11 / 07 / 2018$ & $\begin{array}{l}\text { A Representação Comercial dos EUA (USTR) divulga uma lista de US\$ } 200 \\
\text { bilhões de produtos chineses que podem ser alvo de tarifas extras de } 10 \% \text {. }\end{array}$ \\
\hline 20/07/2018 & $\begin{array}{l}\text { Trump diz que "está pronto" para prosseguir com tarifas sobre importações } \\
\text { chinesas no valor de US } \$ 500 \text { bilhões. }\end{array}$ \\
\hline $31 / 07 / 2018$ & China e EUA sinalizam para um reinício das conversações. \\
\hline 02/08/2018 & $\begin{array}{l}\text { A Representação Comercial dos EUA (USTR) confirma que o presidente Trump } \\
\text { considera aumentar as tarifas de } 10 \% \text { para } 25 \% \text {, totalizando um incremento } \\
\text { de US\$ } 200 \text { bilhões. }\end{array}$ \\
\hline 03/08/2018 & $\begin{array}{l}\text { China anuncia uma lista de US } \$ 60 \text { bilhões em importações dos EUA e planeja } \\
\text { aplicar tarifas caso a administração Trump siga com tarifas mais altas de US\$ } \\
200 \text { bilhões. }\end{array}$ \\
\hline $23 / 08 / 2018$ & $\begin{array}{l}\text { Segunda rodada de tarifas, que complementa os US } \$ 34 \text { bilhões anteriormente } \\
\text { tarifados e culmina em um total de US } \$ 50 \text { bilhões. }\end{array}$ \\
\hline $17 / 09 / 2018$ & $\begin{array}{l}\text { EUA anunciam que tarifas de } 10 \% \text { sobre US\$ } 200 \text { bilhões de exportações } \\
\text { chinesas iniciam em } 24 \text { de setembro e permanecem até o final de } 2018 \text {. }\end{array}$ \\
\hline $18 / 09 / 2018$ & China anuncia retaliação de US $\$ 60$ bilhões de bens dos EUA. \\
\hline $22 / 09 / 2018$ & $\begin{array}{l}\text { China cancela negociações comerciais com os EUA, que visavam a impedir a } \\
\text { implementação de tarifas de US } \$ 200 \text { bilhões sobre produtos chineses. }\end{array}$ \\
\hline 24/09/2018 & $\begin{array}{l}\text { Os EUA implementam tarifas de US } \$ 200 \text { bilhões sobre produtos chineses, } \\
\text { elevando o total de tarifas para US } \$ 250 \text { bilhões. A China aplica tarifas de US\$ } 60 \\
\text { bilhões sobre produtos dos EUA conforme lista divulgada no dia } 3 \text { de agosto. }\end{array}$ \\
\hline
\end{tabular}


continuação...

\begin{tabular}{|c|c|}
\hline Data & Acontecimento \\
\hline $25 / 10 / 2018$ & $\begin{array}{l}\text { Autoridades chinesas e estadunidenses retomam contato. As autoridades estão } \\
\text { se preparando para que Trump e Xi Jinping se encontrem à margem das reuniões } \\
\text { do G20, em novembro, em Buenos Aires. }\end{array}$ \\
\hline $30 / 10 / 2018$ & $\begin{array}{l}\text { Os EUA estão preparados para anunciar tarifas sobre os produtos chineses } \\
\text { remanescentes até o início de dezembro, caso as negociações entre Trump e } \\
\text { Xi Jinping não resultem em um acordo. }\end{array}$ \\
\hline 09/11/2018 & China e EUA retomam negociações comerciais. \\
\hline $19 / 11 / 2018$ & $\begin{array}{l}\text { EUA divulga lista de controles de exportação para tecnologias emergentes. O Bureau } \\
\text { de Indústria e Segurança dos EUA (BIS) publica regras de controle de exportação } \\
\text { para tecnologias como Inteligência Artificial (IA), robótica e computação quântica. }\end{array}$ \\
\hline $02 / 12 / 2018$ & $\begin{array}{l}\text { China e EUA concordam com uma trégua temporária. Essa trégua visa a reduzir } \\
\text { as tensões comerciais, após um jantar de trabalho, na cúpula do G20, em } \\
\text { Buenos Aires. }\end{array}$ \\
\hline $24 / 02 / 2019$ & $\begin{array}{l}\text { Trump anuncia adiamento do aumento de tarifas sobre os US\$ } 200 \text { bilhões de } \\
\text { importações chinesas, até então marcado para o dia } 01 / 05 / 2019 \text {. No caso, as } \\
\text { tarifas aumentariam de } 10 \% \text { para } 25 \% \text {. }\end{array}$ \\
\hline $04 / 2019$ & Expectativa gerada por possibilidade de acordo. \\
\hline 05/05/2019 & $\begin{array}{l}\text { Reversão nas negociações, com Trump confirmando aumento das tarifas para } \\
25 \% \text {, sobre os US } \$ 200 \text { bilhões de importações chinesas, para o dia } 10 / 05 \text {. } \\
\text { Conjuntamente, indica a pretensão de impor tarifas de } 25 \% \text { ao restante dos } \\
\text { produtos chineses não afetados pelas medidas anteriores, atingindo brinquedos, } \\
\text { calçados, roupas e eletrônicos. }\end{array}$ \\
\hline $10 / 05 / 2019$ & $\begin{array}{l}\text { Confirmando ameaça, importações chinesas taxadas em } 10 \% \text {, em setembro } \\
\text { de } 2018 \text {, têm tarifas aumentadas para } 25 \% \text {. }\end{array}$ \\
\hline $13 / 05 / 2019$ & $\begin{array}{l}\text { China anuncia intenção de aumentar tarifas sobre parte dos US\$ } 60 \text { bilhões } \\
\text { de importações americanas designados em setembro. }\end{array}$ \\
\hline $01 / 06 / 2019$ & $\begin{array}{l}\text { China aumenta tarifas sobre US\$ } 36 \text { bilhões do montante de US } \$ 60 \text { bilhões } \\
\text { da lista de importações americanas designadas em setembro de } 2018 \text {. }\end{array}$ \\
\hline 01/08/2019 & $\begin{array}{l}\text { Imediatamente após nova rodada de negociações, Trump anuncia pretensão de } \\
\text { impor tarifas de } 10 \% \text { - e não de } 25 \% \text {, como antes ameaçado - sobre produtos } \\
\text { chineses não listados nos anteriores US } \$ 300 \text { bilhões em importações. }\end{array}$ \\
\hline $13 / 08 / 2019$ & $\begin{array}{l}\text { EUA planejam impor novas taxações em duas etapas: a primeira, em setembro, } \\
\text { taxando em } 10 \% \text { cerca de US } \$ 112 \text { bilhões das importações chinesas; a segunda, } \\
\text { em dezembro, atingindo outros US } \$ 160 \text { bilhões. }\end{array}$ \\
\hline $23 / 08 / 2019$ & $\begin{array}{l}\text { China divulga plano de retaliação sobre US } 75 \text { bilhões em importações } \\
\text { estadunidenses, a serem implementados em setembro e dezembro, respondendo } \\
\text { às taxações americanas. Tarifas sobre os automóveis provenientes dos EUA } \\
\text { aumentariam de } 12,6 \% \text { para } 42,6 \% \text {. No mesmo dia, Trump anuncia subida nas } \\
\text { taxações planejadas para setembro e dezembro, de } 10 \% \text { para } 15 \% \text {, além da } \\
\text { alta das tarifas relativas a US } \$ 250 \text { bilhões de importações chinesas, passando } \\
\text { de } 25 \% \text { para } 30 \% \text { a partir do dia } 1^{\circ} \text { de outubro. }\end{array}$ \\
\hline
\end{tabular}


continuação...

\begin{tabular}{|l|l|}
\hline \multicolumn{1}{|c|}{ Data } & \multicolumn{1}{c|}{ Acontecimento } \\
\hline $11 / 09 / 2019$ & $\begin{array}{l}\text { China anuncia retirada de 16 produtos - menos de US\$2 bilhões das exportações } \\
\text { americanas - da lista de retaliações imposta em 2018. Trump planeja retardar } \\
\text { o aumento de tarifas sobre os US\$ 250 bilhões em importações chinesas, } \\
\text { transferindo-o para o dia 15 de outubro. }\end{array}$ \\
\hline $11 / 10 / 2019$ & $\begin{array}{l}\text { Trump cancela subida de tarifas prevista para outubro, anunciando que as } \\
\text { negociações avançaram para a composição de um futuro acordo. }\end{array}$ \\
\hline $13 / 12 / 2019$ & $\begin{array}{l}\text { Trump anuncia cancelamento das tarifas programadas para o dia 15 de dezembro, } \\
\text { indicando acordo com a China a ser concluído em janeiro de 2020. }\end{array}$ \\
\hline $15 / 01 / 2020$ & $\begin{array}{l}\text { Finalizada a primeira fase do acordo, China concorda em comprar um montante } \\
\text { adicional de US\$ 200 bilhões em produtos americanos. A maioria das tarifas se } \\
\text { mantém, e não são negociadas questões vinculadas aos subsídios e empresas } \\
\text { estatais. }\end{array}$ \\
\hline $03 / 2020$ & $\begin{array}{l}\text { No contexto da crise global desencadeada pela Covid-19, Trump anuncia redução } \\
\text { das taxações sobre produtos chineses vinculados às políticas de contenção à } \\
\text { pandemia. }\end{array}$ \\
\hline
\end{tabular}

Fonte: Wong e Koty (2018) e Bown (2020).

O Quadro 1 nos mostra que, desde julho de 2018, já houve três rodadas de tarifas entre os dois países. Até o momento, os EUA já impuseram tarifas sobre produtos chineses no valor de US $\$ 250$ bilhões e ameaçam impor novas tarifas no valor de US $\$ 237$ bilhões - o que, por sua vez, colocaria sob taxação praticamente todas as exportações chinesas. A China, por sua vez, fixou tarifas de US $\$ 110$ bilhões em produtos dos EUA e está ameaçando impor medidas que afetariam empresas dos EUA que operam na China (Wong e Koty 2018). Já a Quadro 2 busca ilustrar os principais produtos de exportação da China que vem sendo afetados pelas tarifas de importação nos EUA. 
Quadro 2 - Exportações chinesas afetadas pela guerra comercial

\begin{tabular}{|c|c|}
\hline PRIMEIRA E SEGUNDA RODADA (julho e agosto de 2018) & TERCEIRA RODADA (setembro de 2018) \\
\hline Pneus para aeronaves & Carne \\
\hline Reatores nucleares & Peixe e frutos do mar \\
\hline Motores de barco & Produtos animais sem carne \\
\hline Motores de aeronaves e peças de motor & Legumes \\
\hline Compressores de ar e gás & Frutas e nozes \\
\hline Equipamento de aquecimento industrial & Cereais \\
\hline Balanças, principalmente para pesagem de equipamentos & Moinho produtos \\
\hline industriais de grande porte & Sementes oleaginosas \\
\hline Guindastes e equipamentos de elevação & Açúcares e doces \\
\hline Veículos de construção de grande porte & Pães e Massas \\
\hline Peças de perfuração de petróleo e gás & Legumes e frutas preparados \\
\hline Veículos agrícolas & Outros itens alimentares \\
\hline Equipamentos para criação de gado & Bebidas e vinagres \\
\hline Máquinas para processamento de alimentos & Resíduos de processamento de alimentos e ração animal \\
\hline Máquinas para fabricação de papel cartão & Produtos de tabaco \\
\hline Peças de impressoras e copiadoras & Sais e Minerais \\
\hline Máquinas para processamento e moldagem de metais ou & Minérios, escórias e cinzas \\
\hline cimento e suas partes & Combustíveis minerais e óleos \\
\hline Máquinas para fabricação de produtos de vidro & Produtos químicos orgânicos \\
\hline Máquinas para fabricação de artigos de borracha ou plástico & Fertilizantes \\
\hline Rolamentos de esferas & Extratos de curtimento e secagem, corantes e tintas \\
\hline Geradores DC e AC & Óleos essenciais, perfumes \\
\hline Transformadores de eletricidade & Sabonetes e produtos de limpeza \\
\hline Ímãs industriais & Colas, adesivos e enzimas \\
\hline Baterias de lítio e outras baterias & Fluido de isqueiro \\
\hline Fornos e Fornos Industriais & Bens fotográficos \\
\hline Radar e equipamento de rádio & Vários produtos químicos \\
\hline Peças para televisores & Plásticos \\
\hline Equipamento de gravação de vídeo & Borracha \\
\hline Sinais de tráfico eletrônico & Couros crus e couro \\
\hline Equipamentos elétricos (resistores/disjuntores & Madeira \\
\hline LEDs & Produtos de polpa de madeira \\
\hline Trens e peças de trilhos & Papel \\
\hline Veículos de grande porte & Seda \\
\hline Alguns carros e caminhões, motocicletas, helicópteros, & Produtos de cabelo de lã ou animal \\
\hline aviões e espaçonaves & Algodão \\
\hline Microscópios e telescópios & Linho \\
\hline Lasers & Têxteis artificiais \\
\hline Equipamento de imagem e navegação & Outros produtos têxteis \\
\hline Equipamentos médicos (raios-X/marcapassos) & Tecidos \\
\hline Equipamentos científicos, como medidores de pressão e & Chapelaria \\
\hline espectrômetros. & Pedra, gesso, cimento, amianto \\
\hline & Cerâmica \\
\hline & Vidro e vidro \\
\hline & Pedras preciosas e pérolas \\
\hline & Ferro e aço e produtos derivados de metais \\
\hline & Cobre \\
\hline & Níquel \\
\hline & Alumínio \\
\hline & Vários produtos de metal, ferramentas, talheres \\
\hline & Máquinas industriais e de varejo \\
\hline & Eletrônicos \\
\hline & Veículos e peças \\
\hline & Paraquedas \\
\hline & Navios e barcos \\
\hline & Instrumentos para fins científicos ou médicos \\
\hline & Relógios \\
\hline & Móveis, roupas de cama, colchões \\
\hline & Itens sortidos \\
\hline
\end{tabular}

Fonte: Martin e Bryan (2018). 
A primeira e a segunda rodada de tarifas impuseram, respectivamente, tarifas da ordem de US $\$ 34$ bilhões e US $\$ 16$ bilhões - totalizando US $\$ 50$ bilhões. Na primeira rodada, foram incluídos 818 produtos chineses, enquanto que, na segunda, foram incluídos mais 284 produtos. De acordo com o quadro, percebe-se que, na primeira e na segunda rodada, as tarifas se concentraram em mercadorias de setores industriais, sobretudo aqueles beneficiados pelo programa Made in China 2025. Isto é, as tarifas focaram em produtos oriundos de indústrias como aeroespacial, informação e comunicação, robótica, maquinário industrial e automobilística. Já as mercadorias objeto de taxação na terceira rodada, que equivalem ao valor de US $\$ 200$ bilhões, representam uma ampla variedade de produtos, englobando bens de consumo como bonés, TVs e alimentos.

Após o anúncio de novas tarifas no valor de US $\$ 200$ bilhões para exportações chinesas, a China adotou medidas de retaliação contra os produtos estadunidenses. No dia 18 de setembro, o ministro do Comércio da China anunciou que elevaria as tarifas de $5 \%$ a $10 \%$ em US\$ 60 bilhões de produtos, englobando mais de 5.000 bens exportados pelos EUA. As tarifas entraram em vigor no dia 24 de setembro, na mesma data em que as tarifas estadunidenses para produtos chineses começaram a valer. A retaliação chinesa à terceira rodada de tarifas dos EUA colocou um adicional de $5 \%$ sobre produtos como pequenas aeronaves, computadores e têxteis, ao passo em que fixou tarifas adicionais de $10 \%$ em produtos químicos, carne, trigo e vinho. Além desses, houve adição tarifária - entre 5 e $10 \%$ - para produtos como soja, laticínios, suco de laranja, carros elétricos, petróleo, gás natural e equipamentos médicos.

Apesar da trégua estabelecida entre dezembro de 2018 e março de 2019, as escaramuças foram retomadas em seguida. Após ser aventada possibilidade de acordo ao longo de abril de 2019, Trump anunciou, no começo de maio, a elevação das tarifas de $10 \%$ para $25 \%$ sobre os US 200 bilhões de importações já afetadas. Além do mais, também indicou futura expansão das taxações para produtos chineses ainda não alvejados, como brinquedos, calçados, roupas e eletrônicos. Os chineses responderam anunciando que elevariam as tarifas sobre os US $\$ 60$ bilhões de importações estadunidenses, medida que se confirmou no dia primeiro de junho com a elevação de tarifas sobre US $\$ 36$ bilhões do total designado em setembro de 2018.

As ameaças e imposição de taxações seguiram ocorrendo mês após mês, com destaque para as retaliações anunciadas pelos EUA em agosto, atingindo praticamente todos os produtos chineses não incluídos nas medidas anteriores, 
a ser implementada em duas etapas, em setembro e dezembro (Bown e Kolb 2020). A resposta chinesa foi incisiva (ver Quadro 1), e a escalada de tensões forçou a retomada de negociações. Por fim, em dezembro, Trump anunciou o cancelamento das imposições contra produtos chineses agendadas para o mês, devido ao encaminhamento de acordo.

No dia 15 de janeiro de 2020, foi anunciada a primeira fase do acordo, a partir da qual os chineses concordaram em estabelecer cerca de US\$ 200 bilhões em compras adicionais de produtos estadunidenses. Ainda assim, a maioria das altas tarifas foi mantida, e questões vinculadas aos subsídios e às empresas estatais chinesas não entraram nos encaminhamentos (Bown e Lovely 2020). Ao fim da primeira fase do acordo, cabe mencionar que a média das taxações estadunidenses aos produtos chineses se mantém mais de seis vezes superior àquela estabelecida no período anterior ao começo das disputas comerciais, em 2018, ao mesmo tempo em que as imposições chinesas aos produtos americanos também tiveram pequena margem de redução no período pós-acordo (Bown e Lovely 2020).

No contexto da crise global desencadeada pela pandemia do Covid-19, os efeitos da guerra comercial se fizeram sentir de forma mais aguda nos EUA. Particularmente, cabe destacar que, dentre os produtos chineses afetados pelas ondas tarifárias, estavam presentes instrumentos de proteção médica, além de equipamentos de alta tecnologia voltados ao monitoramento de pacientes (Bown 2020). Assim, as exportações chinesas desses produtos foram direcionadas a terceiros mercados, ao mesmo tempo em que os EUA buscaram novos supridores ou, em determinados casos, mantiveram as importações, ainda que os nacionais viessem a pagar valores maiores.

Frente às necessidades inerentes ao panorama da crise, Trump anunciou, nos dias 10 e 12 de março de 2020, a suspensão temporária de determinadas tarifas impostas aos produtos chineses vinculados às atividades de combate à pandemia. Apesar das medidas, cerca de US\$ 1 bilhão em importações potencialmente necessárias ao combate do Covid-19 se mantiveram sob a taxação de $25 \%$ anteriormente imposta. Cabe mencionar que produtos como máscaras hospitalares, roupas protetivas e demais equipamentos de proteção pessoal têm sido exponencialmente demandados, situação que gerou reações de parte dos países exportadores desses materiais (Bown 2020). Nesse sentido, foram impostas restrições às exportações dos mesmos, de forma a assegurar o suprimento interno em caso de necessidade especial. Entre janeiro e o começo de março, mais de 
vinte países tomaram medidas desse caráter, dentre os quais Alemanha, França, Taiwan e Coreia do Sul.

Essa cronologia revela que as retaliações estadunidenses escalam para uma dimensão não apenas restrita às questões comerciais bilaterais. A escolha dos setores e as sanções contra a Huawei - e sua liderança no sistema de comunicação 5G - revelam que há protecionismo e competição em setores high tech. Ou seja, as disputas tarifárias encobrem uma concorrência interempresarial e interestatal pelo domínio dos mais avançados setores técnicos-produtivos entre China e EUA. No limite, como vamos desenvolver na próxima seção, tal domínio é o pomo da competição pela liderança do sistema num contexto de transição. Aí está o entrelaçamento das três dimensões da Guerra Comercial.

\section{A disputa tecnológica e o caso Huawei/5G}

A disputa tecnológica em questão se refere à infraestrutura de comunicação $5 G$, liderada pela empresa chinesa Huawei. Trata-se de uma corporação fundada em 1987, com quase 200 mil funcionários, operando em mais de 170 países e atendendo mais de três bilhões de pessoas em todo o mundo. Cabe destacar que é uma empresa de propriedade integral e exclusiva de seus funcionários, com quase 100 mil acionistas.

As redes $5 \mathrm{G}$ representam um dos pilares das tecnologias high tech priorizadas pela política chinesa do Made in China 2025, tais como segurança cibernética; ferramentas de controle numérico e robótica de ponta; aeroespacial; engenharia oceânica; equipamento ferroviário avançado; veículos de poupança de energia e de nova energia; equipamento de energia; maquinário agrícola; novos materiais; biomedicina e dispositivos médicos de alto desempenho. Como destaca Dodwell (2018), são justamente esses produtos que têm levado o governo estadunidense a adotar medidas protecionistas mais drásticas.

Aliás, diversos documentos oficiais do governo, Estado e instituições privadas estadunidenses revelam suas preocupações. No relatório da Casa Branca de 2018, How China's Economic Aggression Threatens the Technologies and Intellectual Property of the United States and the World, a China é acusada de usar diversas categorias de agressão econômica: protege o mercado doméstico de importações; expande sua projeção em mercados globais através de ferramentas de política industrial e financeira, bem como do apoio às grandes empresas nacionais; 
busca ter acesso seguro aos principais recursos naturais que lhe são essenciais, fortalecer o domínio sobre as indústrias de manufatura tradicionais e adquirir tecnologias-chave e propriedade intelectual de outros países para promover suas indústrias emergentes de alta tecnologia. No mesmo ano, o Office of the U.S. Trade Representative (USTR) publicou o relatório China's acts, policies, and practices related to technology transfer, intellectual property, and innovation. Com base nesse relatório, o USTR determinou que "ações chinesas são irracionais ou discriminatórias” e, portanto, os EUA deveriam restringir o comércio com a China. Entre as ações chinesas, incluem restrições de propriedade estrangeira, requisitos de joint venture e transferência de tecnologia; direção governamental para que empresas chinesas adquiram ativos estratégicos no exterior; realização de inteligência tecnológica, engenharia reversa e roubo de informações sensíveis. A US Chamber of Commerce vem fazendo relatórios recorrentes sobre a escalada técnico-produtiva da China, como um dos mais recentes, intitulado Made in China 2025: global ambitions build on local protections. Na mesma linha, o U.S. Senate Committee on Small Business \& Entrepreneurship publicou o Made in China 2025 and the Future of American Industry exibindo preocupações e prescrições de contramedidas.

O receio da perda de competitividade das indústrias dos EUA tem proporcionado que o governo Trump venha buscando medidas para conter a ascensão chinesa em indústrias avançadas. Não à toa, incluem medidas tarifárias e até a imposição de restrições aos investimentos chineses nos EUA (ISDP, 2018). Aliás, em 2017, o Pentágono alertou que investimentos chineses em empresas estadunidenses que trabalham com software de reconhecimento facial, impressão 3-D, sistemas de realidade virtual e veículos autônomos constituem uma ameaça, uma vez que tais produtos empregam tecnologias que podem ser utilizadas tanto para uso civil quanto para uso militar (McBride, 2018). Além do mais, o Senado dos EUA e o FBI alertaram, em novembro de 2019, os riscos à base industrial do país relacionados às práticas, perpetradas pela China, de recrutar cientistas americanos.

Um exemplo muito ilustrativo do grau de tensão em torno do tema é o fato de que a Diretora Executiva Financeira da Huawei, Meng Wanzhou, filha do fundador da empresa Ren Zhengfeis, encontra-se presa no Canadá, durante uma conexão aérea, desde dezembro de 2018, a pedido da polícia dos EUA, por supostamente violar sanções impostas pelos EUA ao Irã via transações bancárias através do HSBC. A situação deixou o Canadá em uma situação delicada entre 
a pressão norte-americana de extradição e o histórico da relação com a China iniciada por Trudeau (Pierre) pai antes ainda do estabelecimento da relação chinesa com os EUA. Em outros casos semelhantes, a punição é aplicada às empresas supostamente violadoras das sanções, através de multas milionárias, mas não sobre seus diretores individualmente. A prisão de Meng é um típico caso de lawfare com uma série de vícios processuais e violação de direitos, inclusive à defesa, após a executiva ter sido mantida sob interrogatório, por horas, após a prisão, sem nem mesmo saber do que estava sendo acusada. A executiva é literalmente refém de um avançado grau de tensionamento bilateral entre EUA e China e sua prisão funciona como mais um meio de pressão sobre Beijing.

Apesar da condição de superpotência, Washington sabe que Beijing tem meios para resistir e reagir às pressões. Primeiro, há de considerar o lobby dos empresários estadunidenses que exportam da China e daqueles que importam do país asiático. Segundo, há notável interdependência financeira entre ambos países. A China detém títulos do Tesouro dos EUA - US\$ 1,2 trilhão -, financiando os déficits comerciais e orçamentários dos EUA (Chapatta e Greifeld, 2018). É claro que a China não tem interesse na desvalorização do dólar (e de seus ativos), nem em impactar o país que proporciona seus maiores superávits comerciais. De todo modo, a dollar trap trata-se de um instrumento de poder que Beijing pode utilizar com alguma margem de manobra.

As relações bilaterais são complexas e envolvem o padrão tecnológico 5G, ou seja, a infraestrutura para redes de internet móvel de quinta geração. Afinal, o domínio do padrão técnico-produtivo de cada época (geoeconômico) está relacionado com o poder interestatal (geopolítico). Como destacam Arrighi e Silver (2001), os padrões produtivos, tecnológico e organizacional vertebram a competição interempresarial e interestatal nos contextos de transição sistêmica. O fato é que as políticas de ICT (industrial, comercial e tecnológicas) da China replicam expedientes governamentais de outros países ricos em seus respectivos contextos de desenvolvimento e take off industrial e tecnológico, como bem historiciza Chang (2004).

Além da vanguarda técnico-produtiva, o sistema 5G vai potencializar novas formas de uso da força e do soft power, incluindo novos meios para promover operações subterrâneas. Ou seja, os EUA correm o risco de perder também o domínio sobre o controle da informação e seus consequentes sistemas de inteligência. Como destaca Mazzucato (2014), é sabido que a inovação da economia estadunidense combina o acúmulo de gastos públicos 
(sobretudo em setores de defesa do complexo industrial-militar) com o fomento governamental da interação universidade-empresa, como ilustram os avanços tecnológicos recentes nos setores de computação, jatos, energia nuclear, lasers, biotecnologia e fármacos, bem como a própria conformação do Vale do Silício. O próprio caso do Iphone decorreu de gastos governamentais que anteriormente possibilitaram a criação da internet, dos microprocessadores, da bateria de lítio, do GPS, das telas sensíveis ao toque e tecnologias de comunicação (HTTP e HTML), dentre outras ferramentas - acontecimento não muito distinto do caso do algoritmo que levou à criação do mecanismo de busca do Google (Mazzucato 2014).

A ascensão da China se deu a partir de um projeto nacional com políticas de ICT voltadas a desenvolver as forças produtivas, incluindo engenharia reversa, espionagem, etc.. Todas as tecnologias da indústria 4.0 estarão ancoradas na tecnologia 5G, de veículos autônomos a internet das coisas, que, por sua vez, organizará todos os aspectos da vida social, da produção aos serviços públicos e privados. Assim, além do domínio mercadológico sobre infraestrutura tecnológica $5 \mathrm{G}$ e seus equipamentos, tal paradigma tem uso dual - como ilustram as atuais Guerras Híbridas. Com efeito, dada a interligação de toda a vida social ao 5G, é possível potencializar a sabotagem de um sistema bancário, de eleições (Privacidade Hackeada) ou mesmo de uma fábrica - e tudo o mais organizado pela internet das coisas e pela inteligência artificial. O gigantesco processamento de informações pessoais permitirá influir como nunca no mapeamento dos mercados ou na tomada de decisão política.

Os dados dão conta do crescimento das marcas chinesas em smartphones e em infraestrutura de tecnologias 5G. Em smartphones, três das cinco maiores são chinesas (Huawei, Xiaomi, Oppo), sendo que a Huawei caminha rapidamente para a liderança global. No caso da tecnologia 5G, a China caminha para ter a metade do mercado mundial (Huawei com $31 \%$ e ZTE com $11 \%$ ).

Diante dessa projeção chinesa em áreas estratégicas, Washington intensifica as pressões para que seus aliados não construam infraestrutura 5G da Huawei. Para tanto, think tanks ocidentais intensificam a campanha antichinesa. Em relatório recente, tal tecnologia foi colocada sob suspeição por colocar em risco a segurança cibernética dos países, pois as empresas chinesas teriam vínculos com o governo, considerado até um "Estado adversário” (Kaska, Beckvard e Minárik 2019). Ora, conhecendo os sistemas de inteligência e funcionamento do complexo industrial-militar, definitivamente tal argumento não se sustenta. 
Em suma, os conflitos comerciais e tecnológicos EUA-China têm feito o primeiro recrudescer suas posições de força e abandonar espaços multilaterais. Os riscos de crises econômicas e de confrontos geopolíticos colocam a ordem internacional numa encruzilhada (Steinbock 2018). Tudo isso pode se precipitar com a perda da histórica primazia dos EUA em setores de tecnologia de ponta, como as infraestruturas 5G. Está claro, para Washington, que o sistema 5G chinês não é apenas um desafio econômico, mas também uma ameaça geopolítica (Mariani e Bertolini, 2019). Ironicamente, como destacou Arrighi (2008), a expansão financeira do ciclo estadunidense impulsionou o deslocamento do epicentro econômico global do Atlântico Norte para a Ásia Oriental, resultando no renascimento asiático a partir da liderança da reemergente civilização chinesa e da reconstituição do sistema sinocêntrico.

\section{Conclusões}

A batalha de tarifas comerciais é fundamental, pois envolve as duas maiores economias do mundo e, consequentemente, tem múltiplos efeitos. Cada retaliação de lado a lado impacta outros países e seus fluxos comerciais. Mas como sugerimos, a Guerra Comercial pode e deve ser analisada em três níveis. Esse primeiro é crucial, mas com desdobramentos mais imediatos. Contudo, é no nível técnico-produtivo, incluindo as tecnologias da $3^{\text {a }}$ Revolução Industrial e da Indústria 4.0, sobretudo as tecnologias informacionais 5G, que irão se desdobrar as competições interempresariais lideradas por EUA e China. E, esse é o argumento, vai determinar a conformação da competição interestatal e as novas configurações de poder emergentes.

E parece que a estratégia de Washington recente é recrudescer a rivalidade. O recente discurso de Mike Pompeo sobre A China Comunista e o Futuro do Mundo Livre instou "uma luta entre o mundo livre e a tirania" e acusou o Partido Comunista Chinês de ser um "opressor nacional" e um "agente internacional desonesto”. Ou seja, há um intento de recriar uma Nova Guerra Fria, afinal a China é o atual país desafiante da hegemonia estadunidense e comandado por um Partido Comunista de tradições marxistas-leninistas. Ora, os EUA replicam a lógica de contenção como forma de coesionar seus aliados e evitar a expansão do rival, enquanto criam tensões através da Guerra Comercial, do apoio aos movimentos separatistas na China, do cerco militar, etc.. Ironicamente, a ênfase 
da inserção internacional chinesa na atualidade recai exatamente no pragmatismo, no respeito ao princípio da nãointervenção em assuntos domésticos de outras nações, enquanto os EUA instrumentalizam conflitos internos de terceiros países, as ações voltadas à mudança de regimes políticos e a obstrução das ferramentas de concertação política multilaterais.

A Guerra Comercial é parte, pois, de uma encruzilhada e divergência globais. De um lado, os EUA e suas estruturas hegemônicas, conduzidas pelo capital rentista, têm amplificado as desigualdades, a erosão de direitos e o esgarçamento do tecido social e político. De outro, a China se consolida como epicentro da produção e do investimento, como bem ilustra seu projeto de globalização consubstanciado na Nova Rota da Seda. Em outras palavras, a simbiose das relações sino-estadunidenses entrelaça camadas de cooperação e competição, podendo resultar em acomodação, mas também encerrando grande potencial disruptivo, não somente pela divergência dos projetos de globalização, mas pelas contradições típicas dos períodos de transição sistêmica.

\section{Referências}

Arrighi, G. 1996. O longo século XX. Rio de Janeiro: Contratempo.

Arrighi, G. e Silver, B. 2001. Caos e governabilidade no moderno sistema mundial. Rio de Janeiro: Contraponto.

Arrighi, G. 2008. Adam Smith em Pequim. Origens e fundamentos do século XXI. São Paulo: Boitempo, 2008.

Bown C. e Lovely, M. E. 2020. Trump's phase one deal relies on China's state-owned enterprises. Trade \& Investment Policy Watch, 13 de março.

Bown, C. P. 2020. Trump's trade policy is hampering the US fight against COVID-19. Trade \& Investment Policy Watch, 3 de março.

Bown, C.P. e Kolb, M.. 2020. Trump's trade war timeline: an up-to-date guide. Washington: Peterson Institute for International Economics.

Chang, H. J. 2004. Chutando a escada: a estratégia de desenvolvimento em perspectiva histórica. São Paulo: UNESP.

Chappata, B. e Greifeld, K. 2018. Títulos do Tesouro dos EUA como arma na guerra comercial. Bloomberg, 07 de março.

Chernavsky, E. e Leão, R. P. F. 2011. As transformações estruturais do comércio exterior chinês. Brasília: Comunicados do IPEA, no. 97. 
Clinton, H. America's Pacific Century. 2011. Foreign Policy, 11 de outubro.Daojiong, Z. 2015. China's Economic Diplomacy. Focusing on the Asia-Pacific Region. China Quarterly of International Strategic Studies 1, no. 1: 85-104.

Dodwell, D. 2018. The real target of Trump's trade war is 'Made in China 2025'. South China Morning Post, 17 de junho.

Fiori, J. L. 2007. A nova geopolítica das nações e o lugar da Rússia, China, Índia, Brasil e África do Sul. Oikos, no. 8: 77-106.

Institute for Security \& Development Strategy (ISDP). 2018. Made in China 2025. Backgrounder. Junho.

Jinping, X. 2018. A governança da China II. Beijing: Editora de Línguas Estrangeiras., 2018.

Kaska, K.; Beckvard, H. e Minárik, T. 2019. Huawei, 5G and China as a Security Threat. NATO Cooperative Cyber Defence Centre of Excellence (CCDCOE).

Mariani, L. e Bertolini, M. 2019. The US-China 5G Contest: Options for Europe. Istituto Affari Internazionali (IAI).

Martin W. e Bryan B. 2018. China hits back at Trump with tariffs on $\$ 60$ billion of US goods. Business Insider, 18 de setembro.

Mazzucato, M. 2014. O Estado empreendedor: desmascarando o mito do setor público vs. setor privado. São Paulo: Portfolio-Penguin.

McBride, J. 2018. What's Next for the WTO? New York: Council on Foreign Relations. Morrison, W. M. 2018. China-U.S. Trade Issues. Washington: Congressional Research Service.

Murray, A. e Meyer, D. 2020. The Fortune Global 500 is now more Chinese than American. Fortune, 10 de Agosto.

Noland, M. 2018. US Trade Policy in the Trump Administration. Asian Economic Policy Review 13, no. 2: 262-278.

Observatory of Economic Complexity (OEC). Where does China export to? (2017). 2018. Office of the United States Trade Representative. 2018. China's acts, policies, and practices related to technology transfer, intellectual property, and innovation. Washington: Office of the United States Trade Representative.

Organização Mundial do Comércio (OMC). 2020. Trade profiles. China.

Pautasso, D. 2019a. A Nova Rota da Seda e seus desafios securitários: os Estados Unidos e a contenção do eixo Sino-Russo. Estudos Internacionais 7: 85-100. 2019a.

Pautasso, D. 2019b. Desenvolvimento e poder global da China: a política Made in China 2025. Austral: Brazilian Journal of Strategy \& International Relations 18: 183-198.

Pinto, E. 2011. "O eixo sino-americano e as transformações do sistema mundial: tensões e complementaridades comerciais, produtivas e financeiras”. In A China na nova configuração global. Brasília: IPEA. 
Rubio M. 2019. Made in China 2025 and the Future of American Industry. Washington: U.S. Senate Committee on Small Business \& Entrepreneurship.

Steinbock, D. 2018. U.S.-China Trade War and Its Global Impacts. China Quarterly of International Strategic Studies 4, no. 4: 515-542.

Stuenkel, O. 2018. O mundo pós-ocidental - potências emergentes e a ordem global. Rio de Janeiro: Zahar.

US Chamber of Commerce. 2017. Made in China 2025: global ambitions build on local protections. Washington: US Chamber of Commerce.

Yiwei, W. 2016. The Belt and Road Initiative: What Will China Offer the World In Its Rise. Beijing: New World Press.

White House Office of Trade and Manufacturing Policy. 2018. How China's Economic Aggression Threatens the Technologies and Intellectual Property of the United States and the World.

Wong, D. e Koty A. C. 2018. The US-China Trade War: A Timeline. China Briefing, 25 de agosto. 